\title{
P6 acupressure may relieve nausea and vomiting after gynecological surgery: an effectiveness study in 410 women
}

\author{
[L'acupression en P6 peut soulager les nausées et les vomissements postopératoires \\ gynécologiques : une étude d'efficacité auprès de 410 femmes]
}

Aidah Alkaissi RN MSc, ${ }^{*}$ Karin Evertsson RN, ${ }^{*}$ Vivi-Ann Johnsson RN, $†$ Lilli Ofenbartl RN,‡ Sigga Kalman MD PhD*

Purpose: To investigate the effect of sensory stimulation of the P6 point on postoperative nausea and vomiting (PONV) after gynecological surgery in the everyday clinical setting (effectiveness study).

Methods: Four hundred and ten women undergoing general anesthesia for elective gynecological surgery were included in a prospective, consecutive, randomized, multicentre, placebo-controlled, double-blind clinical trial with a reference group. One group was given bilateral P6 acupressure $(n=135)$, a second group similar pressure on bilateral non-acupressure points $(n=139)$, and a third group ( $n=136)$ served as reference group. Nausea (scale 0-6), vomiting, pain, and satisfaction with the treatment were recorded. Primary outcome was complete response, i.e., no nausea, vomiting or rescue medication for $24 \mathrm{hr}$. Results were analyzed by applying logistic regression with indicators of treatments, type of operation and risk score for PONV as explanatory variables.

Results: Complete response was more frequent in the $\mathrm{P} 6 \mathrm{acu}-$ pressure group than in the reference group $(P=0.0194)$ Conversely, the incidence of PONV was $46 \%$ in the reference group, 38\% after pressure on a non-acupoint and 33\% after P6 acupressure. The decrease from $46 \%$ to $33 \%$ was statistically significant. When considering vaginal cases separately, the decrease in PONV was from $36 \%$ to $20 \%$ ( $P=0.0168$ ). The corresponding decrease from $59 \%$ to $55 \%$ in the laparoscopic surgery group was not statistically significant.

Conclusion: P6 acupressure is a non-invasive method that may have a place as prophylactic antiemetic therapy during gynecological surgery.
Objectif : Rechercher l'effet d'une stimulation sensorielle acupressive en P6 sur les nausées et vomissements postopératoires (NVPO) à la suite d'une intervention chirurgicale gynécologique dans un cadre clinique normal (étude d'efficacité).

Méthode : Un essai clinique prospectif, randomisé, multicentrique, en double aveugle contre placebo et comportant un groupe de référence a été réalisé auprès de 410 femmes qui se sont présentées successivement pour une intervention gynécologique non urgente sous anesthésie générale. Les patientes d'un premier groupe ont reçu de l'acupression en P6 ( $n=135)$, celles d'un second groupe ont reçu une pression semblable sur des points bilatéraux, non d'acupression, $(n=139)$ et un troisième groupe $(n=136)$ a servi de référence. Les nausées (échelle de 0-6), les vomissements, la douleur et la satisfaction face au traitement ont été notés. Le premier résultat était une réponse complète, donc absence de nausées, de vomissements ou de médication de secours pendant $24 \mathrm{~h}$. Les résultats ont été analysés par régression logistique avec des indicateurs de traitements, le type d'intervention et le taux de risque de NVPO comme variables explicatives.

Résultats : La réponse complète a été plus fréquente avec l'acupression en $P 6$ que chez les patientes témoins $(P=0,0194)$. Inversement, l'incidence de NVPO a été de $46 \%$ dans le groupe de référence, $38 \%$ après une pression de points non acupresseurs et $33 \%$ après l'acupression en P6. La diminution de $46 \%$ à $33 \%$ était significative. L'examen séparé des cas d'intervention vaginale indique une baisse des NVPO de $36 \%$ à $20 \%(P=0,0168)$. La baisse correspondante de $59 \%$ à $55 \%$ dans les cas d'intervention laparoscopique n'était pas significative.

Conclusion : L'acupression en P6 représente une méthode non effractive de traitement antiémétique prophylactique qui peut avoir sa place pendant une intervention gynécologique.

From the Department of Anaesthesiology and Intensive Care, ${ }^{*}$ University Hospital in Linköping; the Department of Anaesthesiology and Intensive Care $†$ Västervik Hospital; and the Department of Anaesthesiology and Intensive Care, Eksjö Hospital, Linköping, Sweden. Address correspondence to: Dr. Sigga Kalman, Department of Anaesthesiology and Intensive Care, University Hospital in Linköping, S58185 Linköping, Sweden. Phone: +46 132228 71; Fax: +46 132228 36; E-mail: Sigga.Kalman@lio.se Financial support was provided by the County Council of Östergötland (Project F98-305) Sweden. Accepted for publication October 25, 2001.

Revision accepted September 6, 2002. 
$\mathrm{P}$ 6 acupressure, a non-invasive variation of acupuncture, has been proposed as prophylaxis against postoperative nausea and vomiting (PONV). As measures of outcome and methodology differ between studies and most studies are small it remains uncertain whether there is a clinically useful effect of P6 acupressure ${ }^{1-12}$ (Table I).

Our hypothesis was that P6 stimulation increases the number of patients without symptoms of PONV after gynecological surgery in the everyday clinical setting, in contrast to similar pressure on non-acupoint and no treatment.

\section{Patients and methods}

Women $(n=410)$ scheduled for elective gynecological surgery (abortion, dilatation and curettage, conisation or laparoscopic surgery) were included in a prospective, consecutive, multicentre, placebo-controlled, double-blind clinical trial with a reference group. Demographic data are given in Table II. The investigation was approved by the Ethics Committee at our hospital.

\section{Procedure}

After consenting to the study the patients were randomized by sealed envelope to one of the three study groups. A nurse who was not involved in anesthetizing or caring for the patient postoperatively positioned the Seaband (SeaBand ${ }^{\circledR}$, UK Ltd., Leicestershire, England) on both wrists at either the P6 point or on a non-acupoint just before the start of the anesthesia (Figure). The wrists were wrapped for blinding. Anesthetic agents were given at the anesthesiologist's discretion. Details of anesthetics and analgesics administered are listed in Table II. The patients were asked to wear the bands continuously for $24 \mathrm{hr}$. If the band caused discomfort, they could be removed for 30 min every two hours. The reference group received no prophylactic treatment and, therefore, was not blinded. An assessment form was sent to all participating patients, who were asked to record their level of nausea, vomiting, pain at different time points $(8.00$ p.m., 8:00 a.m. and 8:00 p.m.), and satisfaction with the treatment. Nausea was estimated using a seven-point scale (0-6). Primary outcome was complete response, i.e., no report of nausea, vomiting or rescue medication.

The probability of postoperative vomiting was predicted using the Apfel risk score which is based on patient- related factors; age, gender, non-smoking, a history of motion sickness or PONV and estimated duration of anesthesia. ${ }^{13}$

\section{Statistics}

In the logistic regression analysis, the Apfel risk score and the type of operation (laparoscopic or vaginal) were included as explanatory variables. Post hoc, analysis of postoperative morphine requirements was carried out.

Twenty-six patients were withdrawn either because scheduled general anesthesia was changed to local anesthesia $(n=12)$, or an antiemetic was given without the criteria for treatment of PONV being met $(n$ $=14$ ). Criteria for treatment were nausea described as intolerable (as three or more on the 0-6 scale) or the patient vomiting twice. In addition, one patient known for malignant hyperthermia, two patients who were allergic to latex and one who could not read Swedish were withdrawn. These patients were replaced by including another 30 at the end of the study period. Withdrawals were evenly distributed between the groups.

\section{Results}

Risk factors and results for PONV are given in Tables II and III. Less PONV was seen after P6 acupressure than in the reference group $(P=0.0194)$. P6 acupressure did not differ significantly from pressure on a non-acupoint $(P=0.1659)$. The incidence of PONV was $46 \%$ in the reference group, $38 \%$ after pressure on a non-acupoint and 33\% after P6 acupressure.

When the effects of acupressure are evaluated for cases of laparoscopic and vaginal surgery separately in the logistic regression analysis the results are different. After laparoscopic surgery PONV is seen in $59 \%$ of patients in the reference group compared to $55 \%$ in the acupressure group $(P=0.2319)$. The corresponding figures in the vaginal surgery group were $36 \%$ and $20 \%(P=0.01685)$.

A total of 61 adverse events were reported. The bands felt uncomfortable, produced a red indentation or caused itching, $(n=15)$, headache and dizziness $(n$ $=1$ ), or the wrists hurt and the tightness of the band caused swelling or deep marks or blistering at the site of the button $(n=45)$.

Most patients would have liked to receive the same treatment again $(88 \%$ in the reference group, $83 \%$ in the non- acupoint pressure group and $79 \%$ in the P6 stimulation group).

\section{Discussion}

Our objective was to determine if P6 acupressure has an effect in the clinical situation. Thus, we included all patients that met inclusion criteria and did not have contraindications for pressure bands (weight over 110 $\mathrm{kg}$ and/or problems with the wrists) in a multicentre 


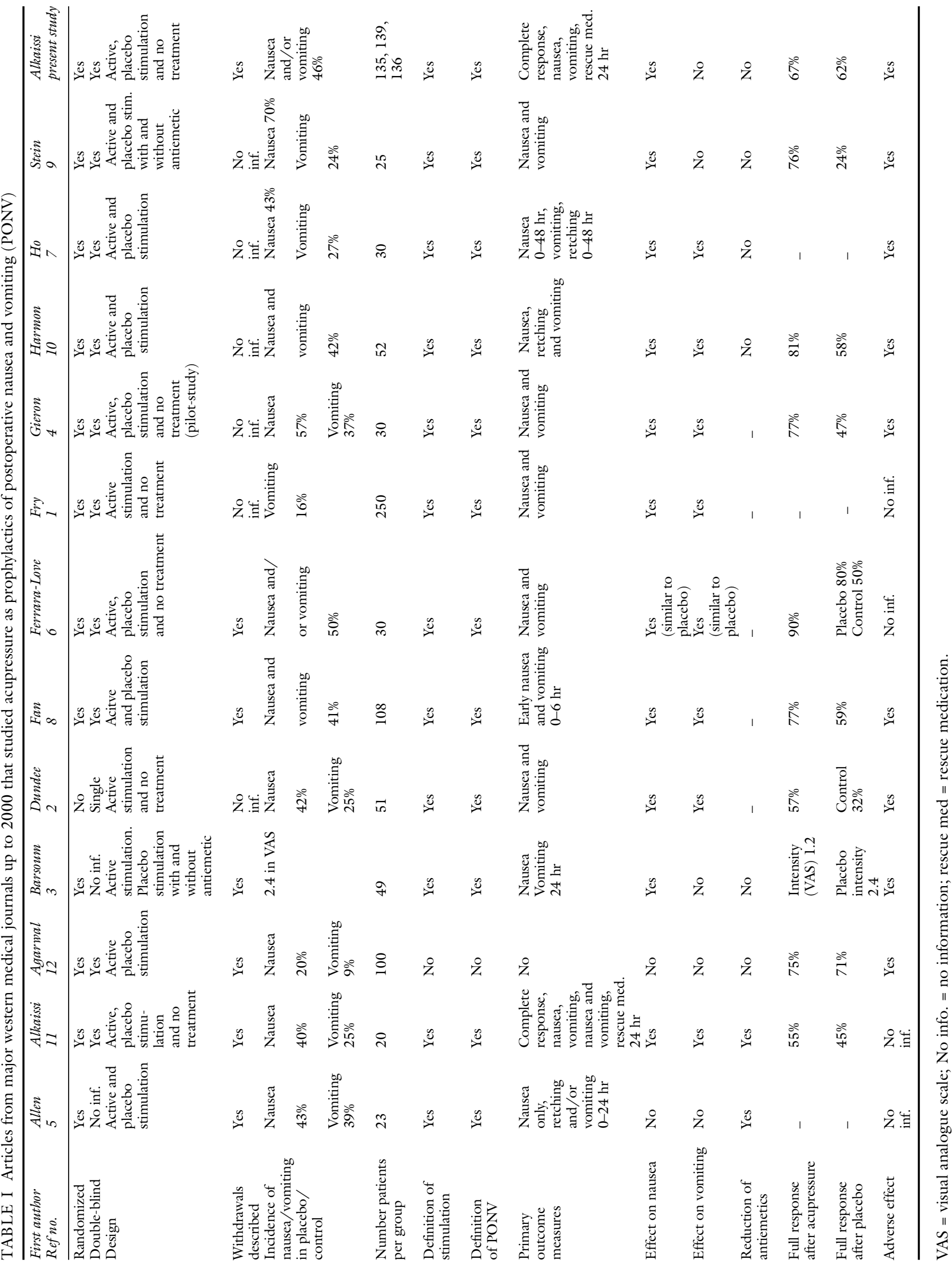


TABLE II Risk factors for postoperative nausea and vomiting, intraoperative and postoperative drugs and time to oral intake and discharge

\begin{tabular}{|c|c|c|c|}
\hline & $\begin{array}{l}\text { P6 acupressure } \\
(n=135)\end{array}$ & $\begin{array}{l}\text { Pressure on a } \\
\text { non-acupoint } \\
(n=139)\end{array}$ & $\begin{array}{l}\text { Reference } \\
(n=136)\end{array}$ \\
\hline \multicolumn{4}{|l|}{ Known risk factors } \\
\hline $\begin{array}{l}\text { Previous postoperative nausea } \\
\text { and vomiting }\end{array}$ & 44 & 49 & 48 \\
\hline Previous motion sickness & 56 & 43 & 42 \\
\hline Pregnant & 25 & 19 & 25 \\
\hline $\begin{array}{l}\text { In the first eight days of menstrual } \\
\text { cycle }\end{array}$ & 19 & 15 & 16 \\
\hline Smoker & 42 & 46 & 35 \\
\hline Apfel risk score & $0.7(0.5)$ & $0.6(0.4)$ & $0.7(0.5)$ \\
\hline \multicolumn{4}{|l|}{ Intraoperative } \\
\hline Propofol & 133 & 135 & 125 \\
\hline Thiopentone & 2 & 5 & 11 \\
\hline Atropine sulphate & 21 & 29 & 25 \\
\hline Glycopyrronium bromide & 13 & 14 & 15 \\
\hline Alfentanil & 78 & 69 & 63 \\
\hline Fentanyl & 54 & 62 & 70 \\
\hline Duration of anesthesia (min) & $35(23)$ & $37(23)$ & $39(26)$ \\
\hline Duration of operation (min) & $24(15)$ & $26(19)$ & $27(21)$ \\
\hline \multicolumn{4}{|l|}{ Postoperative } \\
\hline Pain, visual analogue scale $>3$ & 85 & 84 & 86 \\
\hline $\begin{array}{l}\text { Morphine, postop }(\mathrm{mg}) \text {, median } \\
\text { (maximum) }\end{array}$ & $0(8)$ & $0(12.5)$ & $0(13.5)$ \\
\hline Patients needing morphine & 21 & 27 & 29 \\
\hline Time to oral intake (min) & $77(46)$ & $79(40)$ & $76(57)$ \\
\hline Time to discharge (min) & $110(62)$ & $115(59)$ & $111(57)$ \\
\hline
\end{tabular}

Figures are as number or mean (SD) unless otherwise stated.

study and the study was not stratified for PONV risk factors. We also avoided interference with prevailing hospital routines. For instance, the choice of anesthetic agent was at the anesthesiologist's discretion. To account for any difference in PONV risk between patients, and for differences in incidence of PONV due to gynecological procedures, the Apfel risk score ${ }^{13}$ and the type of operation (laparoscopic/vaginal) were used as explanatory variables in the analysis. We found a slightly lower incidence of PONV in the acupressure group compared to the reference group. Analyzing the results further, the prominent effect appears to be in patients having vaginal surgery.

It was reported recently that there is less pain, PONV and need for opioids when acupuncture is applied during surgery. ${ }^{14}$ Interestingly, if we add postoperative morphine requirement into our logistic regression analysis (patients having more than $2.5 \mathrm{mg}$ morphine postoperatively) we find more patients needed morphine in the reference group $(P=0.0396)$. This could indicate that patients having perioperative P6 acupressure require less analgesia. On the other hand this difference may have occurred by chance.

Lee and Done proposed criteria for a good study on acupressure: the trial should be randomized and double-blinded; the number and the reason for withdrawals should be described; and it should have sufficient power. ${ }^{15}$ They emphasized the importance of describing the operation, the type of anesthesia, and of defining stimulation and the P6 point. The method used to define and document PONV should be reported, primary outcome measures should be defined and adverse effects should be reported. We have reviewed the articles that mention acupressure in adults in journals indexed in Medline and CINAHL up to $2000^{1-12}$ in relation to the criteria suggested by Lee and Done. ${ }^{15}$ The results are summarized in Table I. We have designed our study according to these criteria and have included our results in the Table. Our study is possibly the largest containing a non-acustim- 
TABLE III Effect on postoperative nausea and vomiting (PONV) after P6 acupressure, pressure on a non- acupoint and reference group. Percent of patients having complete response (no nausea, no vomiting, no rescue medication), are also divided into early and late complete response. Percent of patients having PONV, nausea (only), vomiting (only) and rescue medication are given

\begin{tabular}{|c|c|c|c|}
\hline & $\begin{array}{l}\text { P6 acupressure } \\
n=135(51 / 84) \\
\%\end{array}$ & $\begin{array}{l}\text { Pressure on a } \\
\text { non-acupoint } \\
n=139(53 / 86) \\
\%\end{array}$ & $\begin{array}{l}\text { Reference } \\
\begin{array}{l}n=136(61 / 75) \\
\%\end{array}\end{array}$ \\
\hline Complete response & $67 *(45 / 80 *)$ & $62(43 / 73)$ & $54 *(41 / 64 *)$ \\
\hline Early complete response $(0-3 \mathrm{hr})$ & 84 & 83 & 76 \\
\hline Late complete response (3-24 hr) & $75^{*}$ & 67 & 59 * \\
\hline PONV & $33 *(55 / 20 *)$ & $38(57 / 27)$ & $46 *(59 / 36 *)$ \\
\hline Nausea (only) & $24 *(29 / 20 *)$ & $22(26 / 19)$ & $32 *(31 / 32 *)$ \\
\hline Vomiting (only) & $1(0 / 1)$ & $0(0 / 0)$ & $3(3 / 3)$ \\
\hline Rescue medication & $5(8 / 2)$ & $7(11 / 3)$ & $4(7 / 1)$ \\
\hline
\end{tabular}

${ }^{*} P<0.05$ when P6 acupressure is compared to reference group. Figures for all patients and separately after categorization to (laparoscopic/vaginal surgery).

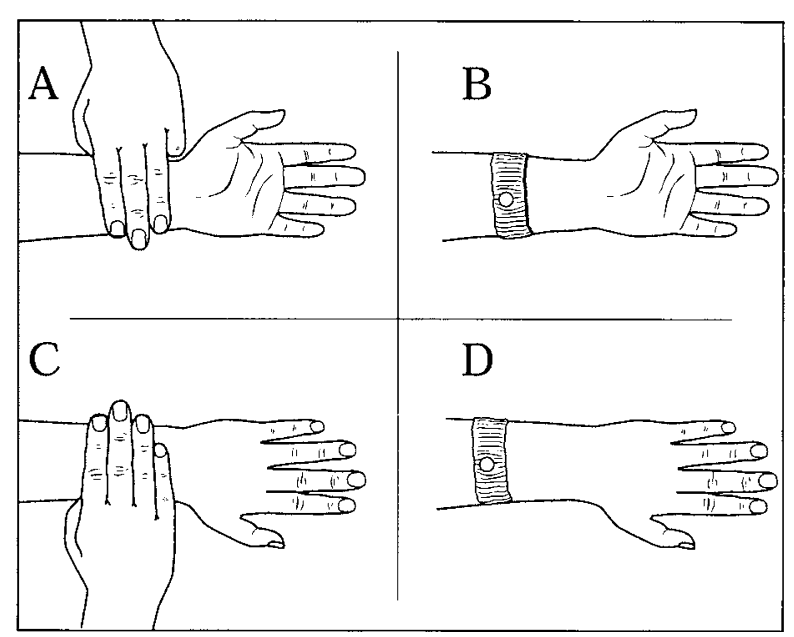

FIGURE Location of points stimulated. A) Pericardium P6 point (Neiguan). Three patient's fingers breadth (approximately $5 \mathrm{~cm}$ proximal to the proximal flexor palmar crease), at a depth of about $1 \mathrm{~cm}$ between the tendons of flexor carpi radialis and palmaris longus. B) Active acupressure. A Seaband (SeaBand ${ }^{\circledR}$, UK Ltd., Leicestershire, England) elastic wristband with a pressure stud (a 7 $\mathrm{mm}$ button) was placed prior to anesthesia over both P6 points. C) Non-acupoint stimulation. A point on the dorsal side of each forearm, four fingers breadth (patient's fingers) proximal to the flexor palmar crease. D) Pressure on a non-acupoint. Seabands were placed prior to anesthesia over the points described under C. ulation group and a control group. ${ }^{4,6,11}$ This design makes it possible to estimate both the placebo effect and the incidence of PONV in the study population.

We conclude that acupressure is a non-invasive method that may be used as PONV prophylaxis during gynecological surgery. Our results would suggest a relative decrease in PONV of $28 \%$ compared to no PONV prophylaxis at all. A significant decrease occurs following vaginal surgery $(44 \%)$ but not after laparoscopic surgery $(7 \%)$.

\section{Acknowledgement}

We thank Erik Leander for valuable discussion, and statistical advice.

\section{References}

1 Fry EN. Acupressure and postoperative vomiting (Letter). Anaesthesia 1986; 41: 661-2.

2 Dundee JW, Ghaly RG, Bill KM, Chestnut WN, Fitzpatrick KT, Lynas AGA. Effect of stimulation of the P6 antiemetic point on postoperative nausea and vomiting. Br J Anaesth 1989; 63: 612-8.

3 Barsoum G, Perry EP, Fraser IA. Postoperative nausea is relieved by acupressure. J R Soc Med 1990; 83: 86-9.

4 Gieron C, Wieland B, von der Laage D, Tolksdorf W. Acupressure in the prevention of postoperative nausea and vomiting (German). Anaesthesist 1993; 42: 221-6.

5 Allen DL, Kitching AJ, Nagle C. P6 acupressure and nausea and vomiting after gynecological surgery. Anaesth Intensive Care 1994; 22: 691-3.

6 Ferrara-Love R, Sekeres L, Bircher NG. Nonpharmacologic treatment of postoperative nausea. J Perianesth Nurs 1996; 11: 378-83. 
7 Ho CM, Hseu SS, Tsai SK, Lee TY. Effect of P-6 acupressure on prevention of nausea and vomiting after epidural morphine for post-cesarean section pain relief. Acta Anaesthesiol Scand 1996; 40: 372-5.

8 Fan CF, Tanhui E, Joshi S, Trivedi S, Hong $\Upsilon$, Shevede K. Acupressure treatment for prevention of postoperative nausea and vomiting. Anesth Analg 1997; 84: 821-5.

9 Stein DJ, Birnbach DJ, Danzer BI, Kuroda MM, Grunebaum A, Thys DM. Acupressure versus intravenous metoclopramide to prevent nausea and vomiting during spinal anesthesia for cesarean section. Anesth Analg 1997; 84: 342-5.

10 Harmon D, Gardiner J, Harrison R, Kelly A. Acupressure and the prevention of nausea and vomiting after laparoscopy. Br J Anaesth 1999; 82: 387-99.

11 Alkaissi A, Stalnert $M$, Kalman $S$. Effect and placebo effect of acupressure (P6) on nausea and vomiting after outpatient gynaecological surgery. Acta Anaesthesiol Scand 1999; 43: 270-4.

12 Agarwal A, Pathak A, Gaur A. Acupressure wristbands do not prevent postoperative nausea and vomiting after urological endoscopic surgery. Can J Anesth 2000; 47: 319-24.
13 Apfel CC, Greim CA, Haubitz I, et al. A risk score to predict the probability of postoperative vomiting in adults. Acta Anaesthesiol Scand 1998; 42: 495-501.

14 Kotani N, Hashimoto H, Sato $\Upsilon$, et al. Preoperative intradermal acupuncture reduces postoperative pain, nausea and vomiting, analgesic requirement, and sympathoadrenal responses. Anesthesiology 2001; 95 : 349-56.

15 Lee A, Done $M L$. The use of nonpharmacologic techniques to prevent postoperative nausea and vomiting: a meta-analysis. Anesth Analg 1999; 88: 1362-9.

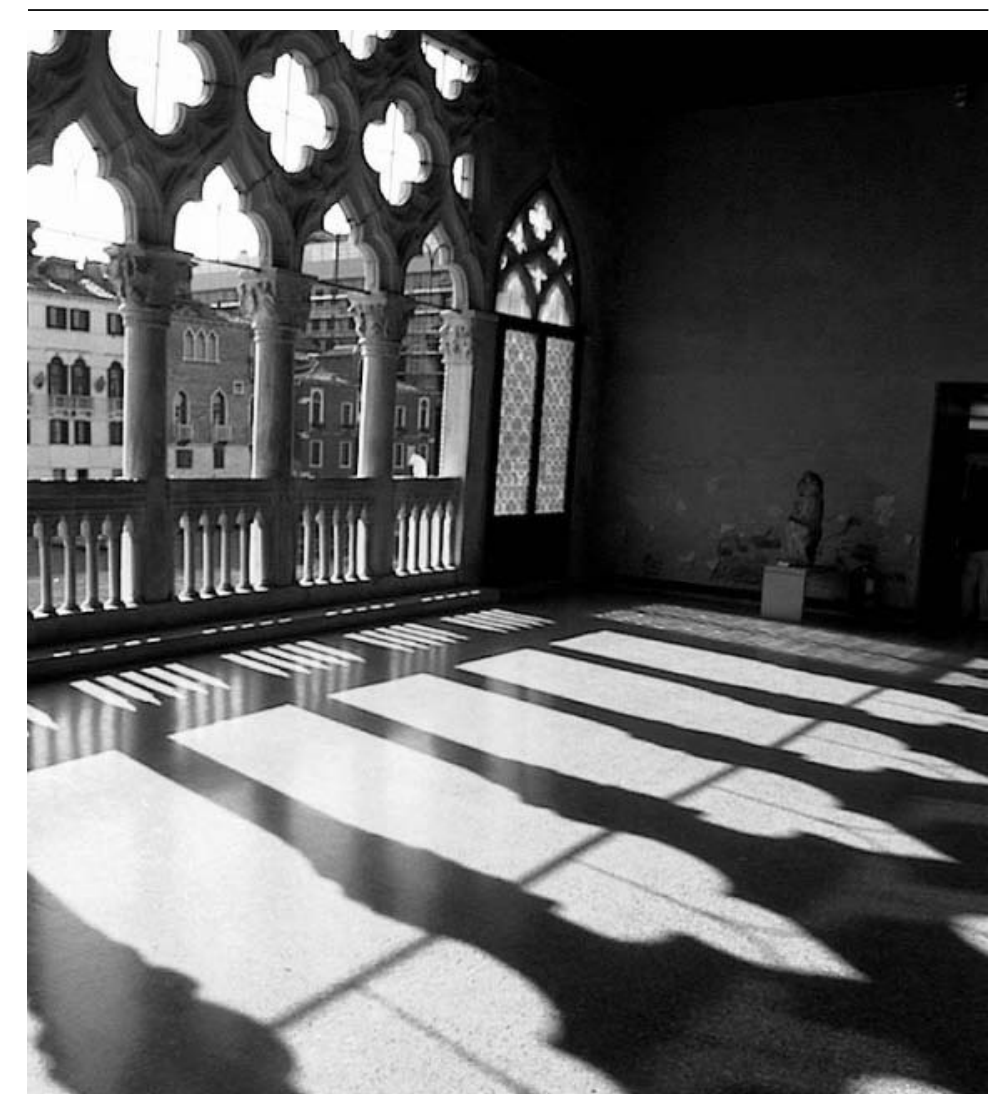

Ca' D'oro - Venice, Italy 